\title{
Jejunal Atresia
}

National Cancer Institute

\section{Source}

National Cancer Institute. Jejunal Atresia. NCI Thesaurus. Code C101027.

A congenital malformation characterized by the absence of a normal opening in a part of the jejunum. 